\title{
Novel AE1 Mutations in Recessive Distal Renal Tubular Acidosis Loss-of-Function Is Rescued by Glycophorin A
}

\author{
Voravarn S. Tanphaichitr, ${ }^{*}$ Achra Sumboonnanonda, ${ }^{\ddagger}$ Hiroshi Ideguchi, ${ }^{\S}$ Chairat Shayakul, ${ }^{\| \S}$ Carlo Brugnara, ${ }^{\uparrow * *}$

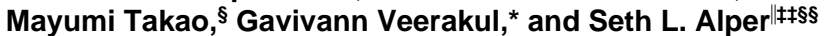 \\ *Divisions of Hematology/Oncology and ${ }^{\ddagger}$ Nephrology, Department of Pediatrics, Siriraj Hospital, Mahidol University, Bangkok 10700 \\ Thailand; ${ }^{\S}$ Department of Clinical Chemistry and Laboratory Medicine, School of Medicine, Fukuoka University, Fukuoka, Japan \\ 814-80; "Molecular Medicine and Renal Units, Beth Israel Deaconess Medical Center, "Department of Laboratory Medicine, The \\ Children's Hospital, and ${ }^{* * D e p a r t m e n t ~ o f ~ P a t h o l o g y, ~}{ }^{\ddagger}$ Department of Cell Biology, and ${ }^{\$}$ Department of Medicine, Harvard Medical \\ School, Boston, Massachusetts 02215
}

\begin{abstract}
The $A E 1$ gene encodes band $3 \mathrm{Cl}^{-} / \mathrm{HCO}_{3}^{-}$exchangers that are expressed both in the erythrocyte and in the acid-secreting, type A intercalated cells of the kidney. Kidney AE1 contributes to urinary acidification by providing the major exit route for $\mathrm{HCO}_{3}{ }^{-}$across the basolateral membrane. Several $A E 1$ mutations cosegregate with dominantly transmitted nonsyndromic renal tubular acidosis (dRTA). However, the modest degree of in vitro hypofunction exhibited by these dRTA-associated mutations fails to explain the disease phenotype in light of the normal urinary acidification associated with the complete loss-of-function exhibited by $A E 1$ mutations linked to dominant spherocytosis. We report here novel $A E 1$ mutations linked to a recessive syndrome of dRTA and hemolytic anemia in which red cell anion transport is normal. Both affected individuals were triply homozygous for two benign mutations M31T and K56E and for the loss-of-function mutation, G701D. AE1 G701D loss-of-function was accompanied by impaired trafficking to the Xenopus oocyte surface. Coexpression with AE1 G701D of the erythroid AE1 chaperonin, glycophorin $\mathrm{A}$, rescued both AE1-mediated $\mathrm{Cl}^{-}$transport and AE1 surface expression in oocytes. The genetic and functional data both suggest that the homozygous AE1 G701D mutation causes recessively transmitted dRTA in this kindred with apparently normal erythroid anion transport. (J. Clin. Invest. 1998. 102:2173-2179.) Key words: kidney • collecting duct $\bullet \mathrm{pH} \cdot$ red cell membrane $\cdot$ Xenopus oocyte $\cdot$ human genetics
\end{abstract}

\section{Introduction}

To maintain acid-base homeostasis, the kidney must reclaim all filtered bicarbonate and excrete additional acid sufficient in quantity to match that produced by systemic metabolism. Although the proximal tubule can reabsorb up to $80-90 \%$ of fil-

Address correspondence to Seth L. Alper, MD, PhD, Molecular Medicine and Renal Units, Beth Israel Deaconess Medical Center, 330 Brookline Ave., Boston, MA 02215. Phone: 617-667-2930; FAX: 617-667-2913; E-mail: salper@bidmc.harvard.edu

Received for publication 13 October 1998.

J. Clin. Invest.

(C) The American Society for Clinical Investigation, Inc. 0021-9738/98/12/2173/07 \$2.00

Volume 102, Number 12, December 1998, 2173-2179

http://www.jci.org tered bicarbonate, the final stage of acid excretion occurs in the distal nephron, mediated largely by type A intercalated cells (IC) ${ }^{1}$ of the cortical and outer medullary collecting ducts. Inherited defects in this urinary acidification process, known as primary distal renal tubular acidosis (dRTA), are manifest by inappropriately alkaline (less than maximally acidified) urine in the presence of systemic metabolic acidosis (complete dRTA) or in response to an imposed acid load (incomplete dRTA) (1). Primary dRTA is inherited in both autosomal dominant and recessive patterns and exhibits a spectrum of clinical severity. Patients frequently present with growth retardation, osteomalacia, nephrocalcinosis, and/or nephrolithiasis $(2,3)$. These latter conditions can predispose to pyelonephritis and eventual renal insufficiency. If detected in time, therapeutic correction of the acidosis by alkali administration leads in most cases to improvement of biochemical abnormalities and resumption of normal growth.

Recently, autosomal dominant dRTA has been found to be associated in several kindreds with mutations in the $A E 1$ gene (4-6). This gene encodes both the erythroid (eAE1) and the kidney (kAE1) isoforms of the band 3 protein (7). eAE1 contributes structurally to red cell integrity (8) and to organismic respiratory function by increasing blood $\mathrm{CO}_{2}$ carrying capacity (7). kAE1 lacks the amino-terminal 65-amino acid residues of eAE1 $(9,10)$ and provides the major exit route for $\mathrm{HCO}_{3}{ }^{-}$in exchange for $\mathrm{Cl}^{-}$across the basolateral membrane of the type A IC during urinary acidification (11).

The few $A E 1$ mutations presently defined in autosomal dominant dRTA include missense mutations in codon R589 (R589H, R589S, R589C) of transmembrane domain 6 (TM6) found in multiple unrelated families $(4,5)$, the S613F mutation in TM7 in one family (4), and an 11-amino acid deletion at the carboxy terminus (6) in one family. Functional analysis of the most extensively studied R589 mutation, however, reveals only modest reductions in AE1-mediated ${ }^{36} \mathrm{Cl}^{-}$transport when expressed in Xenopus oocytes, and the $\mathrm{S} 613$ mutation is associated with upregulation of anion transport. Similarly mild phenotypes are also evident in AE1-mediated sulfate transport in patient red cells. Remarkably, these mild defects are less severe than those associated with AE1 mutations of AE1-deficient autosomal dominant hereditary spherocytosis, a disease not known to be accompanied by classic dRTA $(4,5)$. Thus,

1. Abbreviations used in this paper: DIDS, 4,4'-diisothiocyano-4,4'diisothiocyanostilbene-2,2'-disulfonic acid; dRTA, distal renal tubular acidosis; eAE1, erythroid AE1; GPA, glycophorin A; IC, intercalated cell; kAE1, kidney AE1; RT, reverse transcription; SSCP, single-strand conformational polymorphism; TM6, transmembrane domain 6. 
despite the genetic linkage of dRTA to the AE1 locus and the definition of cosegregating mutations that alter encoded polypeptide sequence, the mechanisms by which mutant AE1 polypeptides cause dRTA remain unclear.

Here, we report a family in which recessively transmitted dRTA is associated with homozygosity for three mutations in the $A E 1$ gene, two of which are novel. AE1 expression and function were studied in red cells of affected and unaffected family members, and in Xenopus oocytes injected with mutant and wild-type cRNA. The data revealed a loss-of-function phenotype of the AE1 mutation that can be rescued by coexpression of the erythroid chaperonin protein, glycophorin A. The functional phenotype of the mutant AE1 polypeptide suffices to explain the clinical phenotype. These functional data are the first to agree with genetic evidence that mutations in the $A E 1$ gene can cause dRTA.

\section{Methods}

Patients. The male proband presented in Thailand at age $3.5 \mathrm{yr}$ with a history of lethargy, anorexia, and slow growth. Physical exam noted height and weight $<3$ rd percentile, pallor, and hepatosplenomegaly. Hypokalemia, hyperchloremic metabolic acidosis, and normal creatinine were accompanied by isosthenuria and alkaline urinary $\mathrm{pH}$, bilateral nephrocalcinosis, and rachitic bone changes. Mild anemia (Hct
$11 \mathrm{~g} / \mathrm{dl}$ ) with microcytosis (MCV $65 \mathrm{fL}$ ), reticulocytosis $(12 \%)$, and a peripheral smear consistent with a xerocytic type of hemolytic anemia (Fig. $1 C$ ), were accompanied by homozygosity for hemoglobin $\mathrm{E}$ ( $\mathrm{Hb} \mathrm{E} / \mathrm{E})$, a clinically benign hemoglobinopathy frequently encountered in Southeast Asia (12).

$3 \mathrm{yr}$ later, the proband's younger sister was evaluated at age $1 \mathrm{yr}$ for delayed growth and exhibited similar findings of hemolytic anemia (Fig. $1 D$ ), nephrocalcinosis, rachitic bone changes, and hypokalemic metabolic acidosis. Both affected sibs failed maximally to concentrate urine after dehydration, were unresponsive to dDAVP, and failed to acidify urine (as determined by urinary $\mathrm{pH}$, anion gaps, and $\mathrm{NH}_{4}{ }^{+}$excretion). These two sibs were diagnosed with complete dRTA and responded to treatment with potassium/sodium citrate (metabolized to bicarbonate).

Both parents were healthy and originated from the Northeast region of Thailand. Consanguinity, growth retardation, and renal or bone disease were notably absent from the family history. Both parents and the unaffected child of normal stature had normal plasma bicarbonate values. The mother and the unaffected child each exhibited normal urinary acidification (to $\mathrm{pH} 5.2$ and 5.3, respectively) after oral ammonium chloride loading. Thus, dRTA was clinically diagnosed as recessively transmitted in this family.

Hemoglobin electrophoresis revealed $\mathrm{Hb} \mathrm{E} / \mathrm{E}$ also in the unaffected sib (II:1) and mother (I:2) and $\mathrm{Hb} \mathrm{A} / \mathrm{E}$ in the father (I:1), but reticulocytosis and evidence of hemolysis were absent from unaffected family members. Red cells of the mother and affected son (II:2) showed similarly reduced osmotic fragility and microcytosis, in contrast to normal values in the father.
A

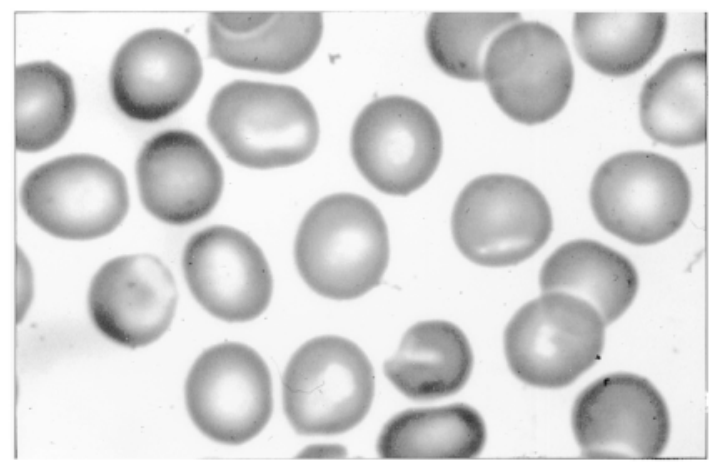

C

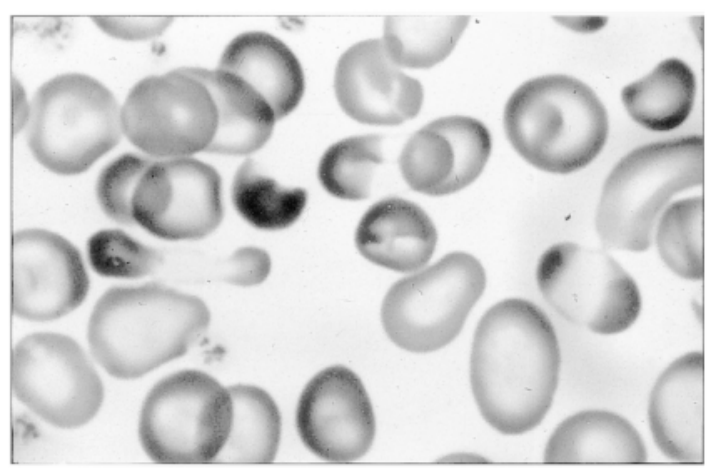

B

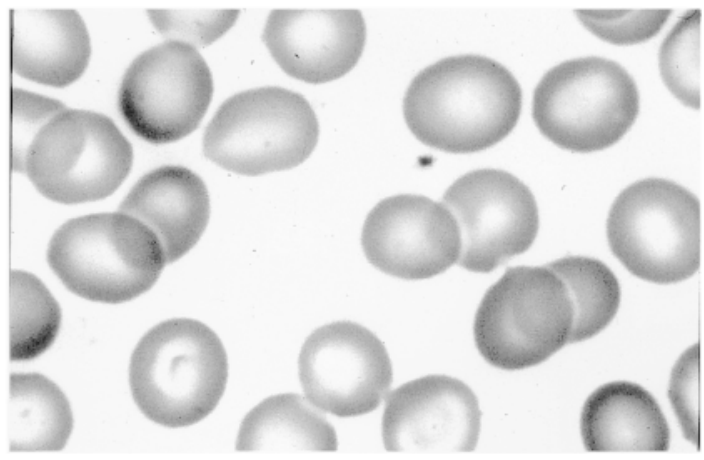

$\mathrm{D}$

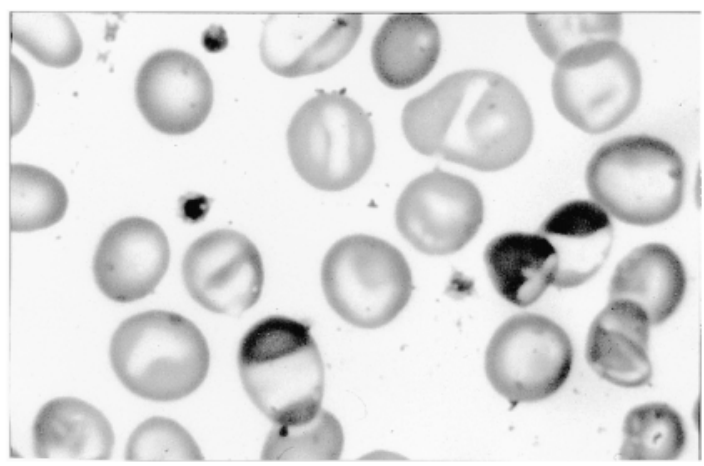

Figure 1. Peripheral blood smears (Wright's stain) from $(A)$ mother I:2, $(B)$ father I:1, $(C)$ affected sib II:3, and $(D)$ proband II:2 (Hb A/E). Target cells, spherocytes, stomatocytes, hypochromia, and anisopoikilocytosis in $A, C$, and $D$ are due to $\mathrm{Hb}$ E/E status. Also present in $C$ and $D$ are xerocyte-like dumbbell forms, and cells with transverse ridges. These last features, along with more extreme microcytosis, basophilic stippling, and polychromasia, differ from typical $\mathrm{Hb}$ E/E blood smears. 
Genetic analysis. Genomic DNA was extracted from peripheral blood leukocytes (SepaGene, Sanko Junyaku, Tokyo). AE1 exons 2-20 (GenBank X77738 and L35930) were PCR-amplified using flanking intronic primers (primer sequences are available from authors upon request). PCR-amplified DNA fragments were subjected to singlestrand conformational polymorphism (SSCP) analysis on mini-slab polyacrylamide gels at $18^{\circ} \mathrm{C}$ and visualized by silver stain (BioRad, Richmond, CA) (13). DNA fragments with abnormal mobilities were directly sequenced or were subcloned (pT7Blue; Novagen, Madison, WI) and $\geq 10$ subclones of each were sequenced with an ABI 373A DNA sequencer (Prism Ready Reaction Dye Deoxy ${ }^{\mathrm{TM}}$ Terminator Cycle Sequencing kit; Applied Biosystems, Foster City, CA). Sequence variants that modified a restriction enzyme cleavage site were assayed in subsequent genomic DNA samples by restriction digestion of the appropriate exonic PCR product.

Analysis of erythrocyte membrane proteins. EDTA-anticoagulated blood from family members and normal controls was shipped on ice to Fukuoka, Japan or Boston, MA. 24-48 h after venipuncture, ghosts were prepared from washed erythrocytes by lysis in 50 vol ice-cold $5 \mathrm{mM}$ Na-phosphate, $\mathrm{pH} 8.0$, containing 0.2 or $1.0 \mathrm{mM}$ phenylmethylsulfonyl-fluoride. Exofacial chymotryptic cleavage of AE1 for detection of the Memphis I polymorphism (14) was achieved by incubation of washed intact erythrocytes at $37^{\circ} \mathrm{C}$ for $30 \mathrm{~min}$ in $140 \mathrm{mM} \mathrm{NaCl}, 10$ $\mathrm{mM} \mathrm{Na}$ phosphate, $\mathrm{pH} 7.4$, (PBS) containing $0.5 \mathrm{mg} / \mathrm{ml}$ chymotrypsin (Sigma, St. Louis, MO). $N$-deglycosylation of membranes with pepti- dyl- $N$-glycosidase F (PNGase F; New England Biolabs, Beverly, MA) for $30 \mathrm{~min}$ at $37^{\circ} \mathrm{C}$, sodium dodecyl sulfate-polyacrylamide gel electrophoresis (SDS-PAGE), and densitometric scanning of Coomassie Blue R250-stained gels were as previously described (5).

Red cell anion transport studies. ${ }^{35} \mathrm{~S}$-sulfate influx studies in the presence and absence of the inhibitor, 4,4'-diisothiocyano-4,4'-diisothiocyanostilbene-2,2'-disulfonic acid (DIDS; Sigma or Calbiochem, La Jolla, CA), were carried out within $48 \mathrm{~h}$ after venipuncture $(5,15)$.

Functional expression of recombinant AE1. Plasmids encoding human eAE1 in pBluscript KS, kAE1 in pXT7 containing the $5^{\prime}$ and $3^{\prime}$-untranslated regions of Xenopus $\beta$-globin, protein 4.2 in pGEM7Zf (gift from C. Korsgren and S.E. Lux, Harvard Medical School) and glycophorin A (GPA; M-allele) in pSG5 (gift from S.L. Spitalnik, University of Pennsylvania, Philadelphia, PA) were described previously $(5,16,17)$. The G701D AE1 cDNA plasmid was constructed by four-primer PCR methods. The flanking primers were F1 (5'-GCCATGATGCTGCGCAAG-3', nt 1903-1920) and F2 (5'-ATAAGTGCATGCGCCAGG-3', nt 2656-2639). The internal mutagenic primers were M1 (5'-GCTCCGACTTCCACCTGG-3', nt 22462263) and M2 (5'-CCAGGTGGA A GTCGGAGC-3', nt 2263-2246). The 754-bp PCR fragment was then cleaved by Fsp I and Sph I and subcloned into similarly cleaved human eAE1 and kAE1 recipient plasmids. The M31T/K56E eAE1 plasmid was constructed by reverse transcription (RT)-PCR from reticulocyte RNA of affected individual II:3. Primers used were 5'-GCCATGGAGGAGCTGC-3' (nt
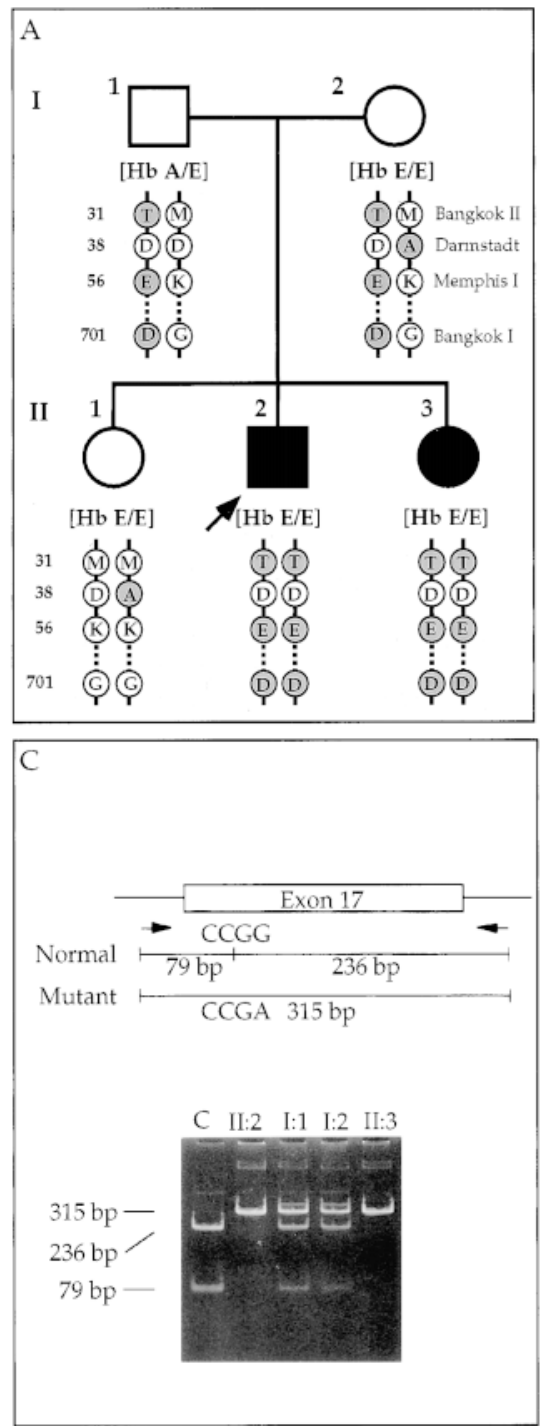
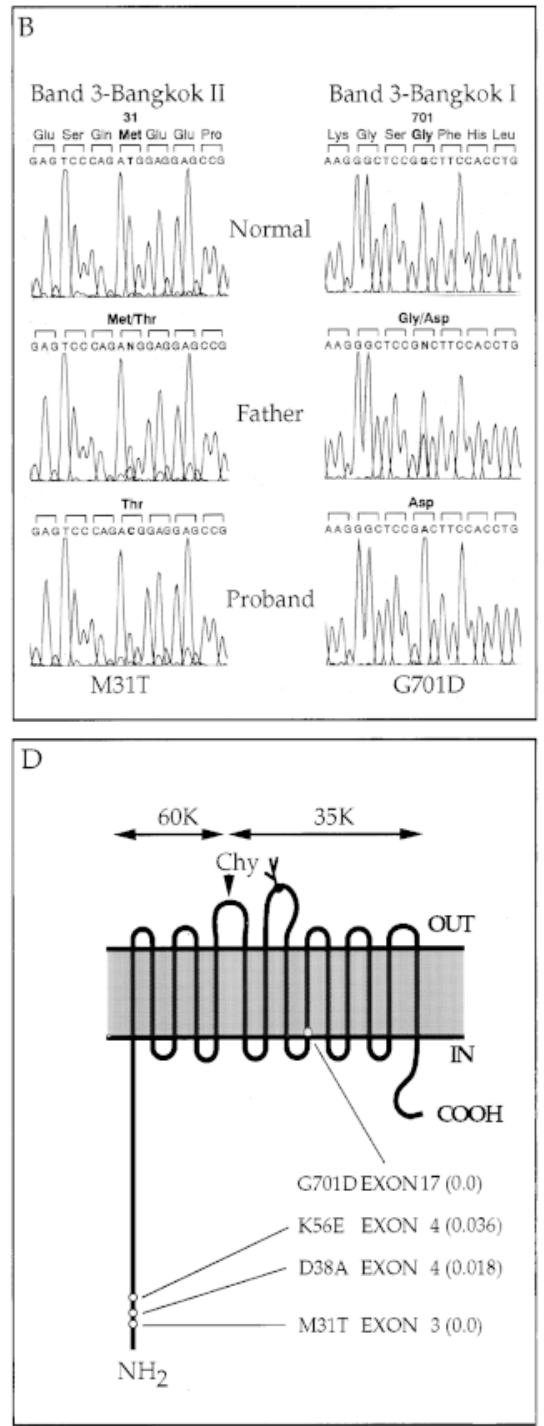

Figure 2. (A) Family pedigree. Proband is indicated by arrow, dRTA by filled symbols. Under each individual are the $\mathrm{Hb}$ genotype and the two AE1 alleles with predicted missense amino acid substitutions indicated by darkened symbols. Amino acid residue numbers are at left. City eponyms for the mutations are at upper right. $(B)$ DNA sequence profiles of the regions adjacent to codons 31 and 701 for a normal control, the heterozygous individual I:1 and the homozygous proband II:2. (C) Restriction fragment length polymorphism analysis to screen for the G701D mutation used the abolition of an Msp I site by the Bangkok I mutation in the PCR-amplified fragment of exon 17. Control genomic DNA $(C)$ is compared with that of indicated family members. $(D)$ Codon substitutions encoded by the four mutations detected in the indicated exons of the AE1 gene of family members are mapped onto a topographic representation of human eAE1 polypeptide. Gene frequencies of the mutations among 55 normal, unrelated Thai individuals are shown within the adjacent parentheses. Human kidney AE1 (kAE1) initiates at Met $66(9,10)$ and so lacks codons 31,38 , and 56 . The site of chymotryptic cleavage of eAE1 in intact red cells is indicated by the arrowhead (Chy), and generates the $\mathrm{N}$-terminal fragments that can distinguish wild-type AE1 (60 kDa) from the K56E (Memphis I) variant $(63 \mathrm{kDa})$. 
148-163) and 5'-CTTTTCCAGAATTCCAGATGG-3' (nt 807-787). The 660-bp PCR product was cleaved by Nco I and Eco RI, then subcloned into similarly cleaved eAE1 recipient plasmids of wild type and G701D type. Integrity of all constructs was confirmed by DNA sequence analysis. cRNAs were transcribed with the Megascript kit (Ambion, Austin, TX). cRNA was injected into defolliculated Xenopus oocytes of stages V-VI. Oocytes maintained in ND-96 buffer at $19^{\circ} \mathrm{C}$ for $2-3 \mathrm{~d}$ were subjected to ${ }^{36} \mathrm{Cl}^{-}$influx studies as described previously (5).

Immunocytochemistry. Cryosections $(6-8 \mu \mathrm{m})$ of Xenopus oocytes previously injected with AE1 cRNA plus or minus GPA cRNA were cut at $-20^{\circ} \mathrm{C}$ and postfixed in acetone for $3 \mathrm{~min}$. After $1 \mathrm{~h}$ preincubation with $\mathrm{PBS} / 1 \% \mathrm{BSA}$, sections were incubated $1 \mathrm{~h}$ at $20^{\circ} \mathrm{C}$ with affinity-purified rabbit polyclonal anti-mouse AE2 antibody crossreactive with the AE1 C-terminal dodecapeptide (18), washed thrice with PBS, and incubated $1 \mathrm{~h}$ with FITC-labeled goat anti-rabbit Ig (Jackson ImmunoResearch, West Grove, PA; 1:1,000). The sections were then washed, reblocked in PBS/1\% BSA, incubated for $1 \mathrm{~h}$ at room temperature with mouse monoclonal anti-GPA antibody $10 \mathrm{~F} / 7$ (16), washed, and stained with Cy3-labeled goat anti-mouse Ig (Jackson ImmunoResearch; 1:1,000). Specificity of the staining was tested in water-injected oocytes. Sections examined with an Olympus BH2 epifluorescence photomicroscope were photographed with Kodak Ektachrome 400 film.

Immunoprecipitation and cell surface biotinylation. Oocytes metabolically labeled for $2 \mathrm{~d}$ with ${ }^{35} \mathrm{~S}$-Translabel (ICN, Costa Mesa, CA) were extracted with $1 \%$ Triton X-100 and subjected to immunoprecipitation with mouse monoclonal anti-human AE1 antibody IVF12 (gift of V. Schuster, Albert Einstein College of Medicine, New York) as described previously, with slight modifications (19). To detect cell surface expression, ${ }^{35} \mathrm{~S}$-labeled oocytes were preincubated in $10 \mathrm{mM}$ $\mathrm{NaIO}_{4}$ at $4^{\circ} \mathrm{C}$ for $30 \mathrm{~min}$, washed, and labeled at $4^{\circ} \mathrm{C}$ for $1 \mathrm{~h}$ with 2 $\mathrm{mM}$ biotin hydrazide (Sigma) in $100 \mathrm{mM} \mathrm{NaOAc}$. Biotinylated oocytes were washed and quenched in a solution containing $5 \mathrm{mM}$ glycine for $10 \mathrm{~min}$, and whole cell extracts were subjected to AE1 immu- noprecipitation. Immune complexes were released from Protein A Sepharose by incubation in acid glycine solution containing $1 \%$ Triton X-100 for $25 \mathrm{~min}$ at $20^{\circ} \mathrm{C}$, and the neutralized supernatant was incubated $1 \mathrm{~h}$ at $4^{\circ} \mathrm{C}$ with avidin-agarose beads (Pierce, Rockford, IL). The beads were washed and resuspended in SDS sample buffer for $1 \mathrm{~h}$ at room temperature. Eluted immunoprecipitates were analyzed by SDS-PAGE and autoradiography.

\section{Results and Discussion}

Detection of AE1 mutations in genomic DNA. Though associations of familial dRTA with cosegregating $A E 1$ mutations have been restricted thus far to cohorts displaying an autosomal dominant inheritance pattern, the combined erythroid and renal phenotype in this family recalled the spherocytosis and acidosis evident in a bovine cohort with a homozygous loss-offunction mutation in $A E 1$ (20), and prompted evaluation of $A E 1$ as the candidate disease gene in this family. SSCP analyses of exonic fragments of the $A E 1$ gene identified anomalous conformers for exons 3,4 , and 17 among the five family members examined.

DNA sequencing revealed three cosegregating missense mutations. Band 3 Bangkok I changes codon 701 in exon 17 from GGC to GAC, ablating an Msp I site (Fig. 2 C), to encode the novel mutation G701D. Band 3 Bangkok II changes codon 31 in exon 3 from ATG to ACG to encode the novel mutation M31T. The third mutation is the known exon 4 polymorphism, band 3 Memphis I (K56E) $(14,21)$, also present in cis with Southeast Asian Ovalocytosis (22) and with numerous spherocytosis mutations $(23,24)$. Both affected individuals were homozygous for these three mutations, whereas both unaffected parents and the one unaffected sister were heterozy-
A

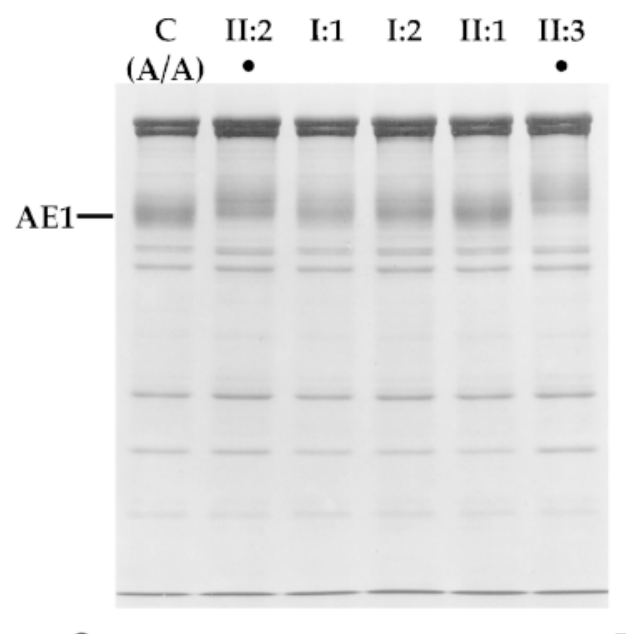

C

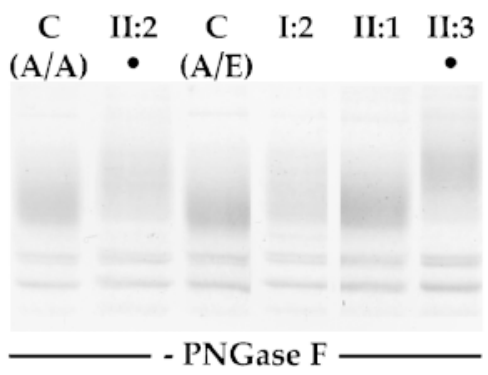

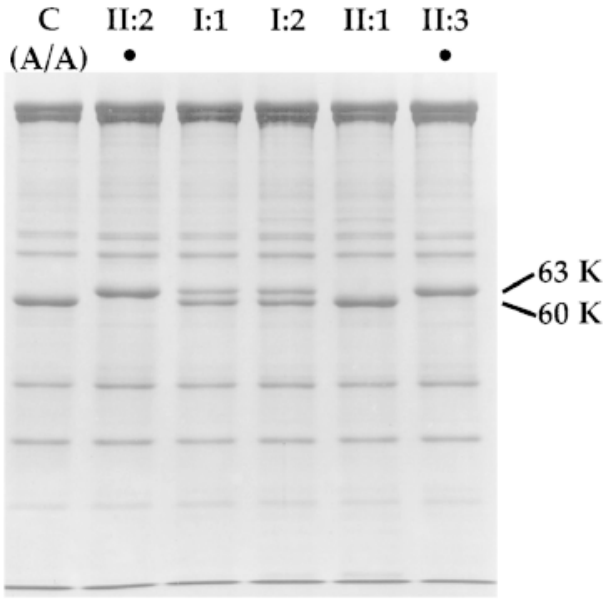

D

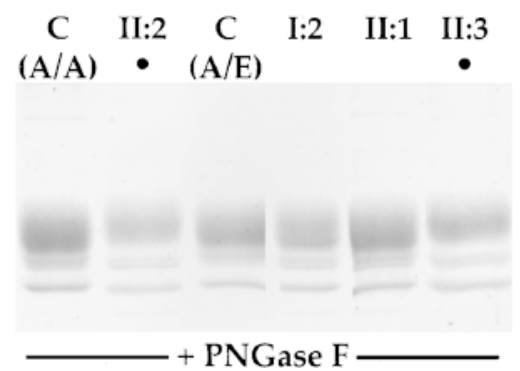

Figure 3. SDS-PAGE-separated, Coomassie Blue-stained red cell ghost polypeptides were prepared from intact red cells $(A)$ or from cells previously treated with chymotrypsin $(B)$. Ghosts from intact red cells were incubated in the absence $(C)$ or presence of PNGase $\mathrm{F}$ $(D)$. Filled circles above lanes indicate affected individuals. 
gous (Fig. 2, $A$ and $B$ ). The mother and unaffected child were also heterozygous in trans for the exon 4 polymorphism, band 3 Darmstadt (D38A) (25). Among these four mutations all expressed in eAE1, only G701D is expressed in the N-terminally truncated $\mathrm{kAE} 1$, and is the sole mutation located in the anion translocating transmembrane domain (Fig. $2 \mathrm{D}$ ). Neither mutation G701D nor M31T was detected in the $A E 1$ genes of clinically normal, unrelated individuals of Thai $(n=55)$ or Japanese origin $(n=48)$. Thai gene frequencies $(n=55)$ were 0.036 for Memphis I variant K56E and 0.118 for Darmstadt variant D38A. Japanese gene frequencies were 0.110 for K56E $(n=123)$ and $0.125(n=36)$ for D38A (26).

Effects of AE1 mutations on red cells. Fig. 3 shows that unaffected and affected family members had comparable contents of AE1 polypeptide $(A)$, with $\mathrm{M}_{\mathrm{r}}$ that varied slightly according to Memphis I (K56E) status $(14,21)$, as further revealed by chymotryptic digestion of intact red cells $(B)$. $N$-deglycosylation of AE1 in intact red cells $(C)$ did not reveal evident differences in $N$-glycan content $(D)$. In addition, DIDS-sensitive sulfate influx in red cells of affected individuals II:2 and II:3 (33.4 and $27.4 \mathrm{mmol} / 10^{13}$ cell $\times \mathrm{h}$ ) did not differ from that in $\mathrm{Hb} \mathrm{E} / \mathrm{E}$ cells from the unaffected mother I:2, unaffected child II:1, or from control $(\mathrm{Hb} \mathrm{A} / \mathrm{E})$ cells (33.0, 32.2 , and $35.5 \mathrm{mmol} / 10^{13}$ cell $\times \mathrm{h}$, respectively). The findings suggest little or no effect of these AE1 mutations on red cell eAE1 anion transport phenotype under the conditions tested.
Functional expression of mutant AE1 polypeptides in Xenopus oocytes. The lack of impaired anion transport in red cells of affected family members differed from the anion transport phenotype of mutant AE1 polypeptides in cRNA-injected Xenopus oocytes (Fig. 4). Consistent with the clinical renal phenotype, recombinant kAE1 G701D function was reduced to $1.7 \%$ and $2.4 \%$ of wild-type values assayed at 20 and $37^{\circ} \mathrm{C}$, respectively (Fig. $4 \mathrm{~A}$ ). The relative transport activities of wild-type and mutant $\mathrm{kAE} 1$ were unchanged in acidic $(\mathrm{pH} 5.5)$ or hypertonic medium (not shown). However, recombinant eAE1 G701D function in Xenopus oocytes was similarly reduced to $11.7 \%\left(20^{\circ} \mathrm{C}\right)$ and $7.2 \%\left(37^{\circ} \mathrm{C}\right)$ of wild-type values, in contrast to the unimpaired transport function in red cells.

To reconcile the mild red cell phenotype with the severe oocyte phenotype of eAE1 G701D, the two additional eAE1 mutations were examined. As shown in Fig. $4 \mathrm{~B}$, the eAE1 double mutant $\mathrm{M} 31 \mathrm{~T} / \mathrm{K} 56 \mathrm{E}$ did not differ in function from wild-type eAE1, nor did the triple mutant M31T/K56E/G701D exhibit any greater transport activity than did the single mutant G701D. Consistent with the recessive clinical phenotype, none of the AE1 mutants exhibited dominant negative properties in oocytes when coexpressed with wild-type AE1 (Fig. 4C).

Rescue of the loss-of-function phenotype of the dRTA mutation. The loss-of-function phenotype of AE1 G701D in Xenopus oocytes can account for the patients' urinary acidification defects but contrasts with their apparently normal red cell sul-
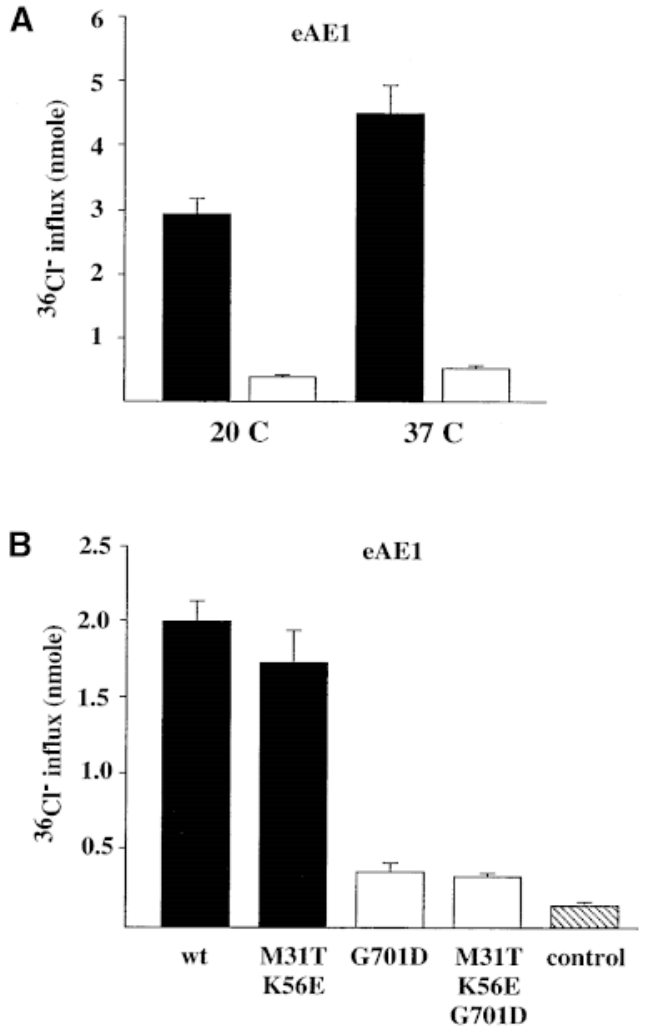
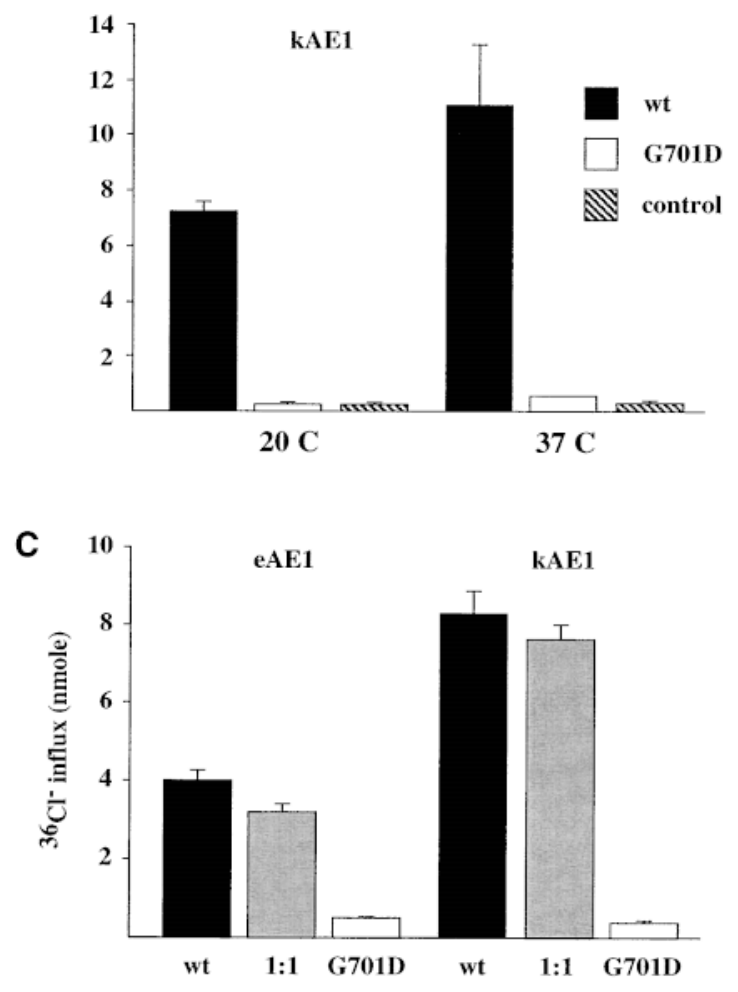

Figure 4. Functional effect of the G701D AE1 mutation. Xenopus oocytes previously injected with water or with cRNA encoding the indicated AE1 polypeptides were subjected to $15 \mathrm{~min}^{36} \mathrm{Cl}^{-}$ influx assays. ( $A$ ) Comparison of ${ }^{36} \mathrm{Cl}^{-}$uptake mediated by wild-type and G701D forms of eAE1 and $\mathrm{kAE} 1$ in isotonic medium, $\mathrm{pH} 7.4$, at 20 or $37^{\circ} \mathrm{C}$, as indicated. $(B)$ Comparison of eAE1-mediated ${ }^{36} \mathrm{Cl}^{-}$ uptake at $20^{\circ} \mathrm{C}$ by wildtype, M31T/K56E, G701D, and triple mutant M31T/ K56E/G701D polypeptides. (C) Comparison of ${ }^{36} \mathrm{Cl}^{-}$influx into oocytes expressing wild-type AE1, AE1 G701D, and 1:1 mixtures of the two indicated no dominant negative effects of G701D AE1. Values are means \pm SEM of uptake pooled from five experiments with six to eight oocytes per group in $(A)$ and two to three experiments in $(B)$ and (C), respectively. $P<$ 0.0001 comparing wildtype with G701D AE1. 

pression of GPA. Oocytes were injected with either

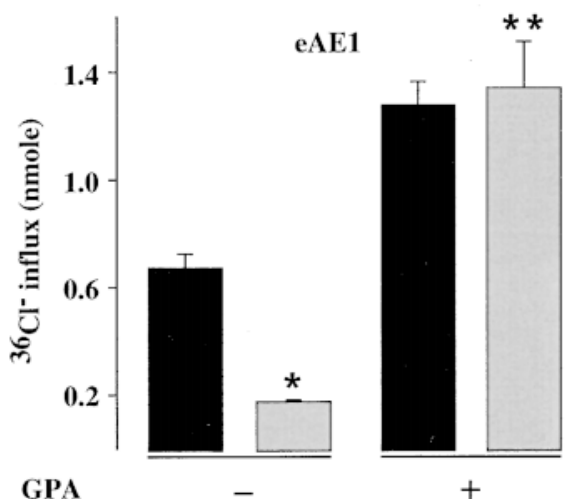

GPA

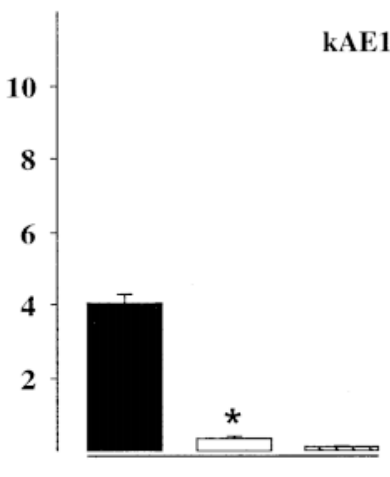

$-$

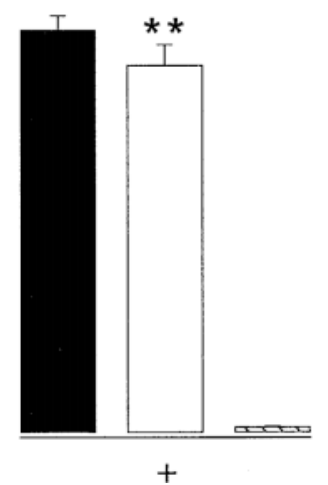
AE1 alone (1.5 ng cRNA) or AE1 plus GPA (1.5 ng, both cRNAs), and ${ }^{36} \mathrm{Cl}^{-}$ uptake was measured 3-4 d later. The data are represented as means \pm SEM from two or three separate experiments with eAE1 and kAE1, respectively (six to eight oocytes per experiment). $* P<0.0001$ compared with wild-type AE1; ** $P>0.05$ compared with wild-type AE1 plus GPA.

fate transport. eAE1 is known to bind to several red cell proteins, including hemoglobin, glycolytic enzymes, ankyrin1, protein 4.2, and GPA (7). Complete deficiencies of protein 4.2 in mouse (27) and human erythrocytes (H. Ideguchi, C. Shayakul, S.L. Alper, and C. Brugnara, unpublished data) and of GPA in human erythrocytes (28) have been associated with decreased AE1 protein and AE1-mediated sulfate transport.

Therefore, the hypothesis was tested that the difference between AE1 G701D function in oocytes and in erythrocytes reflects the different complements of AE1-binding or chaperonin proteins in these cell types. Coexpression of erythroid protein 4.2 did not alter loss-of-function phenotype of eAE1 G701D (not shown). In contrast, the transport activity of AE1 G701D was completely rescued by GPA. $\mathrm{Cl}^{-}$influx mediated by either the eAE1 triple mutant M31T/K56E/G701D or by the kAE1 single mutant G701D was indistinguishable from that of wild-type eAE1 or of kAE1 in the presence of coexpressed GPA (Fig. 5).

Previous studies have shown that coexpression of GPA with wild-type AE1 accelerates, but is not required for, accumulation of AE1 polypeptide at the oocyte surface (29). Thus, it is plausible that a similar mechanism might explain the phenotypic rescue by GPA of AE1 G701D. Immunofluorescence (Fig. 6, $A-D$ ) and cell surface biotinylation studies (Fig. $6 E$ ) revealed much reduced plasma membrane accumulation of AE1 G701D polypeptide compared with that of wild-type AE1. Total accumulation of G701D AE1 was also lower than that of wild-type AE1 after injection of limiting amounts of cRNA (Fig. $6 \mathrm{E}$ ), but this difference was less marked at high AE1 cRNA concentrations (not shown). GPA coexpression increased both total and surface-associated AE1 G701D polypeptide to wild-type levels (Fig. 6, D-E), consistent with the red cell phenotype. GPA levels in red cells of both affected individuals were normal as determined by immunoblot (not shown).

These data indicate that the GPA-AE1 interaction, seemingly optional for wild-type AE1, is rendered essential by the AE1 G701D mutation. Though GPA is expressed in the red cell and GPA mRNA can be detected by RT-PCR in reticulocyte RNA, RT-PCR fails to detect GPA mRNA in human kidney (data not shown). Thus, we postulate that in type A inter-
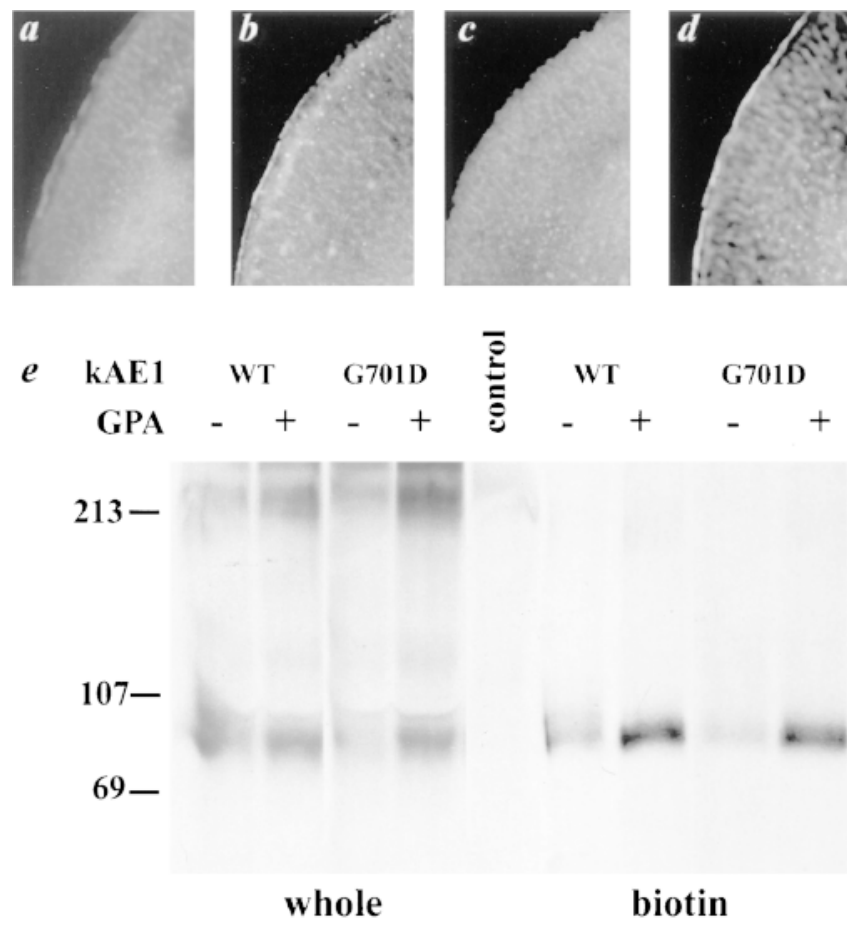

Figure 6. AE1 polypeptide expression in Xenopus oocytes and influence of coexpressed GPA. Immunofluorescence localization of AE1 in the plasma membrane of oocytes expressing wild-type kAE1 ( $a$, minus GPA; $b$, plus GPA) and kAE1 G701D ( $c$, minus GPA; $d$, plus GPA). Sectioning, fixation, incubations, and photomicroscopy were performed under identical conditions. GPA staining intensity at the oocyte surface was equivalent in the presence of wild-type and mutant kAE1 (not shown). Representative of three similar experiments. (e) Expression level of wild-type kAE1 and kAE1 G701D polypeptide in whole oocytes and at the cell surface in the absence and presence of coexpressed GPA. First four lanes show autoradiograph of whole cell lysates from metabolic labeled oocytes after AE1 immunoprecipitation ( $\sim 5$ oocyte equivalents/lane). Last four lanes show products from metabolic labeled oocytes subjected to cell surface biotinylation, AE1 immunoprecipitation and sequential avidin-agarose precipitation (30 oocyte equivalents per lane). Oocytes were injected with water (control) or $1.5 \mathrm{ng}$ AE1 cRNA $\pm 1.5 \mathrm{ng}$ GPA cRNA. One of two similar experiments. 
calated cells lacking GPA, the AE1 G701D mutation produces a conditional phenotype of impaired biosynthetic trafficking and/or protein stability that can be rescued by GPA coexpression.

Elucidation of the mechanism by which the triply mutant AE1 contributes to hemolytic anemia in this family with homozygous $\mathrm{HbE}$ will require further investigation.

In summary, autosomal recessive dRTA in this single, small kindred, in contrast to 17 previously reported recessive or possibly recessive kindreds (6), cosegregates with and is very likely caused by homozygosity for the AE1 mutation G701D. The functional data in oocytes suggest that the G701D mutation leads to decreased or absent kAE1 accumulation at the basolateral plasma membrane of type A IC in the renal collecting duct. The minimal effect of this pathological mutation on red cell eAE1 abundance and sulfate transport likely reflects the presence in red cells of the eAE1 chaperonin, GPA. This is the first reported case of recessive dRTA cosegregating with mutant $A E 1$ and the first in which the functional consequences of the mutation can explain the urinary acidification phenotype. Functional rescue of this conditional $A E 1$ mutation also suggests new therapeutic routes to pharmaceutical and gene therapy of dRTA.

\section{Acknowledgments}

We thank Michelle Rotter, Guido Buchbinder, and Alan StuartTilley for technical assistance, and Leah Staffier for administrative assistance.

This work was supported by National Institutes of Health Grants DK43495 (S.L.A.), HL15157 (C.B. and S.L.A.), and DK34854 (Harvard Digestive Diseases Center to S.L.A.). S.L.A. is an Established Investigator of the American Heart Association.

\section{References}

1. Dubose, T.D., Jr., and R.J. Alpern. 1995. Renal tubular acidosis. In The Metabolic and Molecular Bases of Inherited Disease. C.R. Scriver, A.L. Beaudet, W.S. Sly, and D. Valle, editors. McGraw-Hill, New York. 3655-3689.

2. Nilwarangkur, S., S. Nimmannit, V. Chaovakul, W. Susaengrat, S. Ongaj-Yooth, S. Vasuvattakul, P. Pidetcha, and P. Malasit. 1990. Endemic primary distal renal tubular acidosis in Thailand. Q. J. Med. 74:289-301.

3. Nimmannit, S., P. Malasit, W. Susaengrat, S. Ong-Aj-Yooth, S. Vasuvattakul, P. Pidetcha, C. Shayakul, and S. Nilwarangkur. 1996. Prevalence of endemic distal renal tubular acidosis and renal stone in the northeast of Thailand. Nephron. 72:604-610.

4. Bruce, L.J., D.L. Cope, G.K. Jones, A.E. Schofield, M. Burley, S. Povey, R.J. Unwin, O. Wrong, and M.J. Tanner. 1997. Familial distal renal tubular acidosis is associated with mutations in the red cell anion exchanger (Band 3, AE1) gene. J. Clin. Invest. 100:1693-1707.

5. Jarolim, P., C. Shayakul, D. Prabakaran, L. Jiang, A. Stuart-Tilley, H.L. Rubin, S. Simova, J. Zavadil, J.T. Herrin, J. Brouillette, et al. 1998. Autosomal dominant distal renal tubular acidosis is associated in three families with heterozygosity for the $\mathrm{R} 589 \mathrm{H}$ mutation in the AE1 (band 3) $\mathrm{Cl}^{-} / \mathrm{HCO}_{3}^{-}$exchanger. J. Biol. Chem. 273:6380-6388.

6. Karet, F.E., F.J. Gainza, A.Z. Gyory, R.J. Unwin, O. Wrong, M.J. Tanner, A. Nayir, H. Alpay, F. Santos, S.A. Hulton, et al. 1998. Mutations in the chloride-bicarbonate exchanger gene AE1 cause autosomal dominant but not autosomal recessive distal renal tubular acidosis. Proc. Natl. Acad. Sci. USA. 95: 6337-6342.

7. Alper, S.L. 1994. The band 3-related AE anion exchanger gene family. Cell. Physiol. Biochem. 4:265-281.

8. Peters, L.L., R.A. Shivdasani, S.C. Liu, M. Hanspal, K.M. John, J.M. Gonzalez, C. Brugnara, B. Gwynn, N. Mohandas, S.L. Alper, et al. 1996. Anion exchanger 1 (band 3 ) is required to prevent erythrocyte membrane surface loss but not to form the membrane skeleton. Cell. 86:917-927.
9. Kollert-Jons, A., S. Wagner, S. Hubner, H. Appelhans, and D. Drenckhahn. 1993. Anion exchanger 1 in human kidney and oncocytoma differs from erythroid AE1 in its $\mathrm{NH}_{2}$ terminus. Am. J. Physiol. 265:F813-F821.

10. Brosius, F.C.d., S.L. Alper, A.M. Garcia, and H.F. Lodish. 1989. The major kidney band 3 gene transcript predicts an amino-terminal truncated band 3 polypeptide. J. Biol. Chem. 264:7784-7787.

11. Alper, S.L., J. Natale, S. Gluck, H.F. Lodish, and D. Brown. 1989. Subtypes of intercalated cells in rat kidney collecting duct defined by antibodies against erythroid band 3 and renal vacuolar $\mathrm{H}^{+}$-ATPase. Proc. Natl. Acad. Sci. USA. 86:5429-5433.

12. Wasi, P. 1996. Clinical aspects and screening. In Education Programme of the 26th Congress of the International Society of Hematology. J.R. McArthur, S.H. Lee, J.E.L. Wong, and Y.W. Ong, editors. Panache Design, Singapore. 226-233.

13. Oto, M., S. Miyake, and Y. Yuasa. 1993. Optimization of nonradioisotopic single strand conformational polymorphism analysis with a conventional minislab gel electrophoresis apparatus. Anal. Biochem. 213:19-22.

14. Yannoukakos, D., C. Vasseur, C. Driancourt, Y. Blouquit, J. Delaunay, H. Wajcman, and E. Bursaux. 1991. Human erythrocyte band 3 polymorphism (band 3 Memphis): characterization of the structural modification (Lys 56--Glu) by protein chemistry methods. Blood. 78:1117-1120.

15. Schofield, A.E., D.M. Reardon, and M.J. Tanner. 1992. Defective anion transport activity of the abnormal band 3 in hereditary ovalocytic red blood cells. Nature. 355:836-838

16. Remaley, A.T., M. Ugorski, N. Wu, L. Litzky, S.R. Burger, J.S. Moore M. Fukuda, and S.L. Spitalnik. 1991. Expression of human glycophorin A in wild type and glycosylation-deficient Chinese hamster ovary cells. Role of Nand O-linked glycosylation in cell surface expression. J. Biol. Chem. 266:2417624183.

17. Korsgren, C., J. Lawler, S. Lambert, D. Speicher, and C.M. Cohen. 1990. Complete amino acid sequence and homologies of human erythrocyte membrane protein band 4.2. Proc. Natl. Acad. Sci. USA. 87:613-617.

18. Alper, S.L., A.K. Stuart-Tilley, D. Biemesderfer, B.E. Shmukler, and D. Brown. 1997. Immunolocalization of AE2 anion exchanger in rat kidney. Am. J. Physiol. 273:F601-F614.

19. Chernova, M.N., P. Jarolim, J. Palek, and S.L. Alper. 1995. Overexpression of AE1 Prague, but not of AE1 SAO, inhibits wild-type AE1 trafficking in Xenopus oocytes. J. Membr. Biol. 148:203-210.

20. Inaba, M., A. Yawata, I. Koshino, K. Sato, M. Takeuchi, Y. Takakuwa, S. Manno, Y. Yawata, A. Kanzaki, J. Sakai, et al. 1996. Defective anion transport and marked spherocytosis with membrane instability caused by hereditary total deficiency of red cell band 3 in cattle due to a nonsense mutation. J. Clin. Invest. 97:1804-1817.

21. Jarolim, P., H.L. Rubin, S. Zhai, K.E. Sahr, S.C. Liu, T.J. Mueller, and J. Palek. 1992. Band 3 Memphis: a widespread polymorphism with abnormal electrophoretic mobility of erythrocyte band 3 protein caused by substitution AAG----GAG (Lys----Glu) in codon 56. Blood. 80:1592-1598.

22. Jarolim, P., J. Palek, D. Amato, K. Hassan, P. Sapak, G.T. Nurse, H.L. Rubin, S. Zhai, K.E. Sahr, and S.C. Liu. 1991. Deletion in erythrocyte band 3 gene in malaria-resistant Southeast Asian ovalocytosis. Proc. Natl. Acad. Sci. USA. 88:11022-11026.

23. Jarolim, P., J.L. Murray, H.L. Rubin, W.M. Taylor, J.T. Prchal, S.K. Ballas, L.M. Snyder, L. Chrobak, W.D. Melrose, V. Brabec, et al. 1996. Characterization of 13 novel band 3 gene defects in hereditary spherocytosis with band 3 deficiency. Blood. 88:4366-4374.

24. Jarolim, P., H.L. Rubin, S.C. Liu, M.R. Cho, V. Brabec, L.H. Derick, S.J. Yi, S.T. Saad, S. Alper, C. Brugnara, et al. 1994. Duplication of 10 nucleotides in the erythroid band 3 (AE1) gene in a kindred with hereditary spherocytosis and band 3 protein deficiency (band 3PRAGUE). J. Clin. Invest. 93: 121-130.

25. Miraglia del Giudice, E., A. Vallier, P. Maillet, S. Perrotta, S. Cutillo, A Iolascon, M.J. Tanner, J. Delaunay, and N. Alloisio. 1997. Novel band 3 variants (bands 3 Foggia, Napoli I and Napoli II) associated with hereditary spherocytosis and band 3 deficiency: status of the D38A polymorphism within the EPB3 locus. Br. J. Haematol. 96:70-76.

26. Ideguchi, H., K. Okubo, A. Ishikawa, Y. Futata, and N. Hamasaki. 1992. Band 3-Memphis is associated with a lower transport rate of phosphoenolpyruvate. Br. J. Haematol. 82:122-125.

27. Peters, L.L., B. Gwynn, K.M. John, C. Korsgren, S.L. Ciciotte, C.M. Cohen, S.E. Lux, and C. Brugnara. 1997. Mild spherocytic anemia and altered red blood cell ion transport in mice deficient in protein 4.2. Blood. 90:266a. (Abstr.)

28. Bruce, L.J., J.D. Groves, Y. Okubo, B. Thilaganathan, and M.J. Tanner. 1994. Altered band 3 structure and function in glycophorin A- and B-deficient (MkMk) red blood cells. Blood. 84:916-922.

29. Groves, J.D., and M.J. Tanner. 1992. Glycophorin A facilitates the expression of human band 3-mediated anion transport in Xenopus oocytes. $J$. Biol. Chem. 267:22163-22170. 